\title{
Palliative Care Concepts in Respiratory Disease
}

\author{
D.F. Heigener K.F. Rabe \\ Zentrum für Pneumologie und Thoraxchirurgie, Krankenhaus Grosshansdorf, Grosshansdorf, Germany
}

\section{Key Words}

Chronic obstructive pulmonary disease - Dispnea •

Palliative care $\cdot$ Respiratory disease

\begin{abstract}
Many respiratory diseases besides lung cancer are still not curable. There is an unmet need for palliative care, especially in non-malignant conditions. In this article we focus on symptomatic treatment of typical symptoms in respiratory disease beyond causal treatment.
\end{abstract}

Copyright $\odot 2011$ S. Karger AG, Basel

\section{Introduction}

Albeit the many advantages in the field of respiratory medicine, many diseases still have a grim prognosis. This is not only true for lung cancer but also for severe chronic obstructive pulmonary disease (COPD), interstitial lung diseases, pulmonary hypertension and neuromuscular disorders leading to respiratory failure. Besides curative treatment, there is an unmet need of symptomatic treatment in advanced disease especially for non-malignant conditions. For example, patients with advanced COPD have a similar symptom burden compared to patients with lung cancer [1] and comparable prognosis [2, 3]. However, they have less access to palliative care [4].
In this article, we want to highlight symptomatic treatment options for patients with pulmonary diseases beyond disease-specific therapy.

\section{Dyspnea}

Dyspnea is a common symptom of lung diseases, and patients use variant terms to describe this condition, also conferred to as 'the language of dyspnea': 'chest tightness' is often experienced in coronary disease as well as in bronchoconstriction. 'Rapid shallow breathing' might be a sign of a mismatch between respiratory drive and lung compliance, as in interstitial lung disease. 'Air hunger' might be a sign of increasing carbon dioxide retention as long as ventilatory drive is still a function of the carbon dioxide level in the blood. Some patients complain of not to getting rid of the air, a sign of hyperinflation [5].

Previous articles in this series: 1. Boehler A, Herth FJF: Palliation in lung diseases - facing the challenge and new hope: introduction. Respiration 2011;82:109-110. 2. Gompelmann D, Eberhardt R, Herth FJF: Advanced malignant lung disease: what the specialist can offer. Respiration 2011;82:111-123. 3. Kreuter M, Herth FJF: Supportive and palliative care of advanced nonmalignant lung disease. Respiration 2011;82:307-316. 4. Maio G: Can help for patients be too expansive? Ethical considerations and end-stage lung disease. Respiration 2011;82:395-399.

\section{KARGER}

Fax +4161306 1234

E-Mail karger@karger.ch

www.karger.com
(C) 2011 S. Karger AG, Basel

0025-7931/11/0826-0483\$38.00/0

Accessible online at: www.karger.com/res
Prof. Klaus F. Rabe

Krankenhaus Grosshansdorf, Zentrum für Pneumologie und Thoraxchirurgie Wöhrendamm 80

DE-22927 Grosshansdorf (Germany)

Tel. +49 4102601 151, E-Mail k.f.rabe@kh-grosshansdorf.de 


\section{Non-Pharmacological Approaches to Dyspnea}

\section{Handheld Fans}

The use of handheld fans to produce increased flow to the airways has been investigated by Galbraith and colleagues [6]: 50 patients with dyspnea were randomized to hold a handheld fan towards their nose or to their leg first and then crossed over. The primary endpoint was a reduction of $1 \mathrm{~cm}$ on a $10-\mathrm{cm}$ visual analog scale for dyspnea. There was a significant reduction in the sense of dyspnea in patients holding the device towards their face $(\mathrm{p}=0.003)$. A Cochrane review did not detect a significant benefit for this intervention [7]; however, it was published before the above mentioned work. Because of its low cost it is justified to try this device in a patient with refractory dyspnea.

\section{Noninvasive Mechanical Ventilation}

Noninvasive mechanical ventilation is frequently used in patients experiencing acute or chronic respiratory failure. An advantage over invasive mechanical ventilation is the fact that patients do not need deep sedation and that interruption of treatment is possible. These features help patients to keep their self-determination. Intermittent noninvasive mechanical ventilation in COPD may not prolong life but can improve quality of life measured with different tools [8]. The indications for noninvasive ventilation in chronic respiratory failure due to COPD are outlined in table 1 [9]. There is no reported benefit in patients with restrictive lung diseases and it is questionable whether such measures should be instituted in the terminal phase of an illness. Trials comparing medical treatments with noninvasive ventilation in this situation are lacking.

\section{Walking Aids}

The use of a walking aid like a rollator allows the patient to rest with his arms on the device and thereby activate accessory breathing muscles. Also, the forwardleaning position might alleviate dyspnea [10]. However, evidence for this approach is weak at best [7].

\section{Pulmonary Rehabilitation}

In patients with COPD, the most effective single measure to alleviate dyspnea is pulmonary rehabilitation [11]. Although it does not directly improve gas exchange or lung mechanics, it improves muscle function allowing higher exercise tolerance and thereby reduces lactic acidosis.
Table 1. Indications for intermittend non-invasive ventilation (see text)

Symptoms of ventilatory failure like dyspnoea, fatigue, morning headache

and

Hypercapnia $>55 \mathrm{~mm} \mathrm{Hg}$ in arterial blood

or

Hypercapnia 50-54 mm Hg and nocturnal desaturations

despite supplemental oxygen (2 liters/min)

or

Hypercapnia 50-54 mm Hg and at least two hospitalizations per year due to hypercapnic exazerbation

Another benefit of exercise training is the diminished ventilatory demand resulting in a lower respiratory rate. Thereby expiration is prolonged and dynamic hyperinflation reduced [12].

\section{Pharmacological Approaches to Dyspnea}

\section{Oxygen}

Patients with dyspnea often request supplemental oxygen. However, benefit in terms of prolonged survival depends on a number of factors which were identified more than 30 years ago in a trial by the Nocturnal Oxygen Therapy Trial Group: 203 patients with COPD and hypoxemia were randomized in one group receiving nocturnal oxygen for approximately $12 \mathrm{~h} /$ day and in another group receiving continuous oxygen. The risk of death was 1.94-fold higher in the nocturnal oxygen group compared to the continuous oxygen group with a 2-year mortality of $40.8 \%$ in the former group compared to $22.4 \%$ in the latter, as long as oxygen use exceeds $16 \mathrm{~h} /$ day. This effect was seen irrespective of the presence or absence of hypercapnia [13]. In another trial, 87 patients with COPD, hypoxemia and carbon dioxide retention were randomized to either oxygen supplementation at a rate of $2 \mathrm{l} / \mathrm{min}$ for at least $15 \mathrm{~h} /$ day or no oxygen supplementation. Fiveyear mortality was reduced in the oxygen group (45.2\%) compared to the control group (66.7\%) [14].

Evidence of supplemental oxygen in interstitial lung diseases is sparse if present at all: in a trial by Strom and Boman [15], 240 patients with parenchymal lung disease and supplemental oxygen therapy were followed for 28 months. There was no control group, and many patients had restrictive lung disease due to sequelae of tuberculosis with deformities of the chest wall. Also, COPD was present as a comorbidity in many patients. Low $\mathrm{pCO}_{2}$ 
Table 2. Key studies regarding long-term oxygen therapy

\begin{tabular}{|c|c|c|c|c|c|}
\hline Study & NOTT & MRC & Górecka et al. [17] & Fletcher et al. [18] & Chaouat et al. [19] \\
\hline $\mathrm{n}$ & 203 & 87 & 135 & 38 & 76 \\
\hline Mean $\mathrm{pO}_{2}(\mathrm{~mm} \mathrm{Hg})$ pre & 44 & 54 & 59 & $<60$, nocturnal desaturation & 56-69, nocturnal desaturation \\
\hline Duration of observation & 19 months & 60 months & 36 months & 36 months & 35 months \\
\hline Hours on oxygen per day & 16 & 15 & 15 & nocturnal & nocturnal. \\
\hline Parameter & Mortality & Mortality & Mortality & Mortality/PAP & Mortality/PAP \\
\hline Results & $+(40.8$ vs. $22.4 \%)$ & $+(66.7$ vs. $45.2 \%)$ & negative & negative & negative \\
\hline
\end{tabular}

$(<5.5 \mathrm{kPa})$, poor performance status and the presence of interstitial fibrosis were predictors of poor outcome. Although there is no evidence for prolonged survival in this patient group, exercise tolerance is improved with supplemental oxygen at higher flow rates [16].

The German guideline for long-term oxygen therapy states that patients must have hypoxemia ( $\leq 55 \mathrm{~mm} \mathrm{Hg}$ partial pressure of oxygen in arterial blood gas) or right heart failure with an arterial blood gas $<60 \mathrm{~mm} \mathrm{Hg}$ [16] (table 2). These conditions are seldom fulfilled. The question is whether supplemental oxygen at least relieves dyspnea in patients not matching the above mentioned criteria. In a randomized trial, patients with refractory dyspnea, incurable disease and a partial pressure of oxygen $>7.3 \mathrm{kPa}$ (approximately $55 \mathrm{~mm} \mathrm{Hg}$ ) were randomly assigned to oxygen or room air delivered by a nasal cannula with a flow of $2 \mathrm{l} / \mathrm{min}$, at least $15 \mathrm{~h}$ daily for 7 days. The dyspnea on day 6 changed by -0.9 points (on a 1 - to 10-point scale, with 10 denoting maximum dyspnea) in the oxygen group compared to -0.7 in the room air group representing a nonsignificant difference $(\mathrm{p}=0.554)$. Drowsiness was more frequently reported in the room air group (13 vs. $10 \%$ ), as well as nasal irritation (6 versus $2 \%$ ). These findings do not justify the use of oxygen in this patient group [20].

\section{Opioides}

The only drugs with a proven effect on dyspnea are opioids. Opioid receptors are found in high densities in the brain stem and may exert an inhibitory influence on respiratory drive mainly mediated by $\mu$-receptors. Moreover, opioids have anxiolytic properties further diminishing dyspnea. Opioid receptors in the lung itself are also postulated, because nebulized inhaled morphine seems to have a moderate effect on dyspnea [21, 22]. However, only systemically administered morphine has a significant measurable effect on dyspnea at rest $(-0.9$ on a scale of 1-10, with 10 denoting maximum dyspnea) [23] and the precise mechanism of action is not known yet. Routes of administration depend on the severity of the symptom. In acute dyspnea, opioids should be given intravenously or subcutaneously; intranasal or buccal fentanyl is a reasonable alternative. Chronic dyspnea can be alleviated by slow-release formulations given on a regular schedule.

\section{Benzodiazepines}

Benzodiazepines do not have a significant effect on dyspnea itself but they diminish anxiety as a trigger of acute dyspnea, thereby breaking the vicious circle of anxiety and dyspnea.

In a trial of alprazolam in chronic dyspnea there was no benefit observed: 29 patients were randomized to $0.5 \mathrm{mg}$ of alprazolam twice daily or placebo. There was no difference in chronic dyspnea as measured with the Medical Research Council score and no improvement in distance in the 12-min walking test [24]. In this trial, although drowsiness occurred, benzodiazepines were well tolerated.

\section{Neuroleptic Drugs and Antidepressants}

Neuroleptic drugs like chlorpromazine were studied in COPD patients, but the results were conflicting [25]. The same accounts for antidepressant drugs, so their use cannot be recommended for the relief of dyspnea [10].

\section{Cough}

Cough is initiated by rapidly adapting 'irritant' receptors located in the larynx and major airways, especially at the branching points of the tracheobronchial tree. They can be stimulated by a variety of factors like smoke, histamine or foreign bodies. Its physiological task is clearance of the airways from foreign bodies or mucus. In healthy subjects, cough accounts for approximately $2.5 \%$ of mucociliary clearance while in patients with chronic bronchitis it accounts for 20\% [26]. It is important to assess whether the cough is productive or not and if there is any identifiable trigger or time in which cough occurs. 
Also, a thorough review of a patient's medication is of paramount importance. By doing this, causal treatment of this symptom is sometimes possible, i.e. by identifying asthma or a particular medication (i.e. angiotensin-converting enzyme inhibitors) as the cause. Unfortunately, the majority of patients with advanced pulmonary disease need symptomatic treatment as outlined below.

\section{Non-Pharmacological Approaches to Cough}

Cough is a physiological mechanism to clear the airways. Making cough more effective is therefore a reasonable approach for alleviating this symptom. Evidence regarding non-pharmacological approaches to cough stems from trials conducted 20-30 years ago. One method is manual compression of the chest by a second person during the expiratory phase of coughing and thereby enhancing the peak expiratory flow. But besides the drawback of needing a second person for this maneuver, it is not applicable for patients with a stiff chest or after abdominal surgery. Other physiotherapeutic opportunities are postural drainage and thoracic vibration. With postural drainage, gravity is used to improve mucociliary clearance by positioning the patient head down. However, there is only sparse evidence for patients with cystic fibrosis indicating that postural drainage may help. For other diseases, the benefit is uncertain. Thoracic vibration is sometimes used in addition to postural drainage. Again, there are sparse and conflicting data regarding the efficacy of this approach. The frequencies of the used devices in the studies differ, making comparison even more difficult $[27,28]$. A pipe-like device called 'Flutter' uses the same principle: in the pipe, a steel ball oscillates by breathing into the mouthpiece and thereby generates vibrations in the airways. The oscillation can be modulated by changing the inclination of the pipe. Again, evidence of efficacy is sparse [29].

Application of positive expiratory pressure (PEP) via a face mask during cough showed disappointing results in patients with cough due to chronic bronchitis. Forty-seven patients with COPD and hypersecretion were randomized to at least 45-min daily treatment with PEP with either 10 or $0 \mathrm{~mm} \mathrm{Hg}$ (placebo). After 6 months of treatment, the amount of sputum and dyspnea was similar in both groups. Dyspnea on exertion and cough significantly improved in the placebo group. Therefore, the authors did not recommend the use of PEP masks [30]. However, in another report from the same year, 43 patients with COPD were allocated to standard physiotherapy or PEP used twice daily. PEP resulted in improvement of cough and less mucus production [31]. In a meta-analysis regarding patients with cystic fibrosis [32], the authors concluded that PEP was equally effective as standard physiotherapy.

\section{Pharmacological Approaches to Cough}

Existing evidence is on a low level or even only expert opinion. Medications to treat cough can be divided into two categories: those making cough more effective and those inhibiting the cough reflex.

The so-called 'mucolytics' N-acetylcysteine and ambroxol are frequently prescribed in acute cough. However, well-controlled clinical trials documenting a benefit in chronic cough do not exist and even the mechanism of action is not known [33].

Centrally acting inhibitors of the cough reflex include non-opioid drugs like dextromethorphan and opioid drugs, mainly codeine and its derivatives as well as morphine. In a small crossover trial with 16 patients suffering from chronic cough, either $20 \mathrm{mg}$ of codeine or dextromethorphan was given daily. Cough frequency was lowered equally in both groups; however, the intensity was significantly lowered in a greater degree with dextromethorphan $(\mathrm{p}<0.0008)$. Patients thus considered dextromethorphan to be the better antitussive $(\mathrm{p}<0.001)$ [34]. However, because of the low number of patients, these results have to be viewed with caution. Another observational trial included no more than 8 patients comparing $30 \mathrm{mg}$ of codeine to $60 \mathrm{mg}$ of dextromethorphan and found both regimens equally effective [35]. Again, the number of patients precludes significant conclusions.

Slow-release morphine was investigated in a doubleblind, crossover trial including 27 patients. Inclusion criteria were cough of $>3$-month duration and failure of specific therapy. Patients were randomized to either $5 \mathrm{mg}$ of slow-release morphine twice daily or placebo. A reduction of $40 \%$ in daily cough scores was achieved with daily morphine ( $p<0.01$ compared to placebo) [36]. There is no evidence for a dose-dependent effect of opiates nor is there any superiority proven for any specific opioid over another [37].

Giving systemic steroids ( $30 \mathrm{mg}$ daily for 2 weeks) is always worth a try, especially in patients with cancer [37]. Inhaled steroids seem to be effective only in the presence of airway inflammation and had no effect on non-asthmatic cough [38].

Inhaled ipratropium bromide blocks the efferent limb of the cough reflex and alters mucociliary factors and 
Table 3. Drugs against cough

\begin{tabular}{|c|c|}
\hline Drug & Proposed dosage \\
\hline Dextromethorphane & $10-15 \mathrm{mg}$ two to four times daily \\
\hline Codeine & $30-60 \mathrm{mg}$ four times daily \\
\hline Morphine & $\begin{array}{l}5-10 \mathrm{mg} \text { of slow-release formula twice } \\
\text { daily }\end{array}$ \\
\hline Prednisolone & 30 mg daily for two weeks \\
\hline Nebulised lidocaine & $5 \mathrm{ml}$ of $0.2 \%$ solution twice daily \\
\hline $\begin{array}{l}\text { Inhaled ipatropium } \\
\text { bromide }\end{array}$ & $\begin{array}{l}500 \mu \mathrm{g} \text { in } 2 \mathrm{ml} \text { solution four times } \\
\text { daily }\end{array}$ \\
\hline
\end{tabular}

Adapted from Molassiotis et al. [37].

Table 4. Possible contributing factors to fatigue

\begin{tabular}{ll}
\hline Factor & Example \\
\hline Side effects of medication & $\begin{array}{l}\text { chemotherapy, opiates, } \\
\text { metoclopramide } \\
\text { hypothyroidism, hypogonadism } \\
\text { depression } \\
\text { hypercalcemia, hypoxemia, } \\
\text { Endocrine aberrations } \\
\text { Comorbidities }\end{array}$ \\
Metabolic alterations & $\begin{array}{l}\text { interleukin 1, interleukin } 6^{1} \\
\text { pneumonia }\end{array}$ \\
Cytokines & Infection
\end{tabular}

${ }^{1}[41]$.

thereby decreases stimulation of cough receptors. However, the only evidence comes from a group of 14 patients with chronic persistent cough following an upper respiratory tract infection: in a crossover design, $320 \mu \mathrm{g}$ of inhaled ipratropium daily significantly reduced day- and nighttime symptoms. Notably, bronchial hyperreagibility was ruled out by methacholine testing [39].

Inhaled local anesthetics are recommended for cancer-related cough in a review by Molassiotis and colleagues [37]. This approach has to be used with caution because of the possibility of reflex bronchospasm. The patient should avoid oral intake for at least $1 \mathrm{~h}$ after inhalation because of the anesthetized pharynx and the possibility of aspiration.

Table 3 summarizes the available drugs for symptomatic treatment of cough.

Palliative Care Concepts in Respiratory Disease

\section{Fatigue}

Fatigue is a main symptom of malignant conditions, especially in lung cancer. But also in nonmalignant pulmonary diseases, fatigue is a major issue. Fatigue is defined as tiredness in a physical, emotional or cognitive dimension which is out of proportion to the recent activity and interferes with the activities of daily living [40]. It is a condition caused by multiple factors (table 4); many of them are poorly understood. To identify a treatable cause is the first step encountering this problem. One should consider hypoxemia, dehydration, electrolyte imbalances - especially hypercalcemia in malignant conditions -, hypothyroidism and anemia as possible triggers. It is mandatory to inquire for depression as well. In many cases, no treatable cause will be identified or treatment of the assumed cause does not relieve the symptom.

\section{Non-Pharmacological Approaches to Fatigue}

There are several approaches to treat fatigue with different underlying pathophysiological assumptions, summarized in the PACE Study by White and colleagues [42] regarding the chronic fatigue syndrome: if one considers fatigue to be a true lack of energy, adaptive pacing (APT) is a reasonable strategy. It is a behavioral therapy guiding the patient to plan and pace activities and thereby reducing or avoiding fatigue. Cognitive behavior therapy (CBT) is based on the assumption of a vicious circle of fear of fatigue and avoidance of activity perpetuating fatigue. Patients are advised to gradually increase mental and physical activities after they have learned about their baseline energy level in experimental tasks. If one considers fatigue to be a result of physical deconditioning due to the underlying illness, graduate exercise therapy (GET) makes sense. Patients increment their daily exercise (i.e. walking) in predefined steps avoiding overexertion.

These three approaches haven been compared to each other as well as to specialist medical care (SMC) which consists of explaining the nature of fatigue to the patient and counseling, for example to avoid extreme periods of rest or exercise. Six hundred and forty-one eligible patients were randomized to APT (160 patients), CBT (161 patients), GET (160 patients) and SMC alone (160 patients). Fatigue was significantly reduced with CBT (3.4 points on the Chalder fatigue questionnaire from 0 to 33 where the lowest score is least fatigue; $95 \%$ CI 1.8-5.0; $\mathrm{p}=0.0001$ ) and GET (3.2 points; 95\% CI 1.7-4.8; $\mathrm{p}=$ $0.0003)$ compared to SMC alone. There was no difference between APT ( 0.7 points; $95 \%$ CI -0.9 to $2.3 ; \mathrm{p}=0.38$ ) and $\mathrm{SMC}$ alone. Also, the mean physical function scores im- 
proved significantly with CBT and GET compared to SMC alone but not with APC.

A major limitation of this study is the fact that chronic fatigue syndrome per definition precludes fatigue in organic disease and it is not known whether these results also apply to the latter patient group.

Another non-pharmacologic approach, especially in patients with COPD, is pulmonary rehabilitation. Besides many other beneficial effects, pulmonary rehabilitation can alleviate fatigue: in a recently published study, a cohort of 81 male patients with COPD was followed regarding a change in the disease-specific quality of life. The dyspnea, mastery, emotion and fatigue domains of the Chronic Respiratory Questionnaire Self-Reported were measured from baseline to completion of pulmonary rehabilitation. A significant reduction in fatigue after pulmonary rehabilitation was observed $(\mathrm{p}=0.017)$ [43].

\section{Pharmacological Approaches to Fatigue}

Drug treatment of fatigue is almost exclusively investigated in cancer patients. To the knowledge of the authors, no relevant trials of fatigue treatment in nonmalignant disease exist.

In the case of fatigue accompanied by a low hemoglobin level $(<10 \mathrm{~g} / \mathrm{dl})$, a blood transfusion can sometimes ameliorate this clinical symptom. In a feasibility study, 30 patients with cancer-related fatigue and anemia answered two different fatigue scales (the Functional Assessment of Cancer Therapy Fatigue and the Brief Fatigue Inventory) before and 3 days after a blood transfusion. There was a significant improvement in both scales measured after transfusion [44].

Administration of colony-stimulating factors is investigated in cancer patients, as guidelines regarding this issue exist. However, the use of erythropoietin and its analogues has major drawbacks: the onset of action is delayed for several weeks after injection, there is concern of increased tumor growth in cancer-related anemia and the costs are high. These drugs are thus only recommended in chemotherapy-related anemia [45].

Methylphenidate is a phenethylamine with indirect sympathicomimetic properties. This centrally acting drug possesses structural similarities to amphetamine and as a psychostimulant is used in attention-deficit hyperactivity disorder but also - off label - in cancer-related fatigue. A large phase III trial compared the administration of methylphenidate to placebo: 74 patients in each arm received either $54 \mathrm{mg}$ of extended release methylphenidate or placebo for 4 weeks. The primary endpoint was a subjective change in the patient's fatigue measured by the Brief Fatigue Inventory. In the whole cohort, there was no difference after 4 weeks in the two groups ( $\mathrm{p}=$ 0.317 ). However, in the patients with worst fatigue, there was a trend for an improved outcome in the methylphenidate group. Typical side effects of methylphenidate are nervousness and loss of appetite [46].

In a meta-analysis on pharmacological treatment of cancer-related fatigue - published before the above mentioned study - methylphenidate had a small but significant beneficial effect on fatigue [47]. However, these results do not apply to nonmalignant respiratory diseases where no nonspecific treatments of fatigue have been investigated.

\section{Cachexia}

Cachexia occurs in cancer patients as well as in patients with nonmalignant lung diseases, i.e. COPD.

In COPD, the term 'pulmonary cachexia' is frequently used but only vaguely defined as a loss of lean body mass regardless of calorie intake. Although the mean body mass index (BMI) in COPD patients is overall not different from healthy subjects with values between 25 and 26 $[48,49]$ the distribution is different, with a larger portion of underweight subjects. In a cohort of patients with moderate to severe COPD, the prevalence of nutritional depletion [defined as BMI $\leq 21$ and/or fat-free mass index $\leq 15$ (in females) or $\leq 16$ (in males)] was high (27\%) [50].

The causes of pulmonary cachexia are not completely understood. Postulated mechanisms include elevated total caloric expenditure due to higher respiratory effort, inefficient metabolization of substrates and increased levels of proinflammatory cytokines [51]. A low BMI is an independent risk factor for a poor prognosis in COPD [52]. This is possibly due to a loss of muscle mass and associated low exercise tolerance.

Cachexia in cancer has not been defined precisely, thus making comparisons of results of clinical trial populations difficult. This problem has recently been addressed by an international consensus conference. A key issue in this process was the description of a continuum with three defined stages rather than a single state. Pre-cachexia is defined as an anorectic state with weight loss of $\leq 5 \%$ of body weight. This can transit into cachexia, defined as weight loss of $>5$ or $>2 \%$ in patients with a preexisting low BMI of $\leq 20$ or sarcopenia. The latest stage in this definition is refractory cachexia which is defined by a therapy-resistant, procatabolic underlying illness with poor performance status und a survival prognosis of $<3$ months [53]. 


\section{Non-Pharmacologic Approaches to Cachexia}

\section{Noninvasive Ventilation}

The implementation of noninvasive positive pressure ventilation (NPPV) might reverse pulmonary cachexia. In a cohort study, 141 patients with severe chronic respiratory failure due to COPD changes in BMI were evaluated between baseline, 6 and 12 months after initiation of NPPV. Overall, $20.6 \%$ of patients had a BMI $<20$ at baseline. These were the patients with the most severe respiratory impairment: there was a very high negative correlation between BMI and hyperinflation $(\mathrm{r}=-0.55, \mathrm{p}<$ $0.001)$. In the patient group with a BMI $<20$, NPPV resulted in a significant weight gain of $6.2 \%(\mathrm{p}<0.05)$ at 6 months and $12.8 \%(\mathrm{p}<0.01)$ at 12 months, respectively. No weight gain was observed in subjects who had a BMI $\geq 20$ [54]. In the whole study population, no correlation between BMI change and changes in other values of lung function like inspiratory muscle strength or blood gas values was observed. However, a major drawback of the study was the lack of a control group not receiving NPPV.

\section{Counseling of Patients and Relatives}

In cancer patients, relatives are more concerned about the patient's weight loss than the patients themselves. Especially in refractory cachexia, it is of paramount importance to help the family cope with this problem. Facing the poor prognosis, it should be avoided to force the patient to eat although there is no feeling of hunger. It should be explained that in this phase of the disease, the demand of nutrition is of very low importance because it will not alter the course of the disease. Relatives and friends should accept this instead of trying to make the patient eat.

\section{Pharmacological Approaches to Cachexia}

Cachexia as a complex syndrome can be addressed in several ways. First, one can try to increase appetite with ghrelin and its analogues, megestrol acetate or tetrahydrocannabinol (THC). Second, considering cachexia as an inflammatory state, targeting the acute-phase reaction with nonsteroidal anti-inflammatory drugs or steroids is reasonable. Third, the use of other drugs (whose mechanism of action on cachexia is not understood), i.e. the antidepressant mirtazapine, was investigated. To date, no drug is approved for treatment of cachexia due to respiratory diseases or cancer in the European Union.

Palliative Care Concepts in Respiratory Disease

\section{Ghrelin and Anamorelin}

The activation of ghrelin receptors stimulates appetite and increases lean body mass. However, because of its short half-life, ghrelin has to be administered by the parenteral route. This is not feasible in clinical practice. Anamorelin is an orally available non-peptidic drug, which mimics the N-terminal, active region of ghrelin. In 32 healthy volunteers, anamorelin resulted in dose-dependent weight gain [55]. Further studies with this drug in cancer patients are planned.

\section{Megestrol Acetate}

Megestrol acetate is a derivative of progesterone. In cancer patients, the administration of megestrol acetate results in increased appetite and weight gain. However, there was no improvement in survival or quality of life [56]. Thus, relying on the available data, megestrol acetate cannot be recommended for the treatment of cancer cachexia.

\section{Tetrahydrocannabinol}

The plant Cannabis sativa contains about 60 cannabinoids including THC and cannabidiol. Whereas THC has antiemetic and psychoactive effects, cannabidiol attenuates the psychotropic effects of THC and has anti-inflammatory properties. These drugs reportedly increase appetite. In a three-arm study, the effect of THC was compared to cannabis extract and placebo. The primary endpoint was a gain of appetite and quality of life with THC and cannabis extract compared to placebo. However, all groups reported similar proportions of patients with increased appetite (THC 58\%, cannabis extract 73\% and placebo 69\%) resulting in an early termination of the study due to futility [57]. This makes cannabinoids a very questionable option for the treatment of cancer-related cachexia.

\section{Mirtazapine}

The antidepressant drug mirtazapine was associated with an increase in appetite. However, only a small study with 17 non-depressive patients with cancer-related fatigue exists. Twenty-four percent of these patients experienced weight gain with a dose of $15-30 \mathrm{mg}$ daily [58]. These results do not justify the use of mirtazapine on a broad basis in cancer-related cachexia. Further studies are clearly needed.

\section{Steroids and Nonsteroidal Anti-Inflammatory Drugs}

Steroids have long been used for a variety of complaints in terminally ill patients. Dyspnea and fatigue as 
well as cachexia are potential conditions treated with these drugs. Considering cachexia as an inflammatory condition, the use of steroids or other anti-inflammatory drugs makes sense. In a quite old paper by Lundholm and colleagues [58], 135 patients with malnutrition and various types of cancer were randomized into three groups: $10 \mathrm{mg}$ of methylprednisolone, $50 \mathrm{mg}$ of indomethacin or placebo daily. The primary endpoint was overall survival. Anti-inflammatory treatment indeed improved overall survival compared to placebo $(\mathrm{p}=0.03)$; however, measures of weight gain or appetite were not reported [59]. In daily practice, we indeed observe an improvement in appetite in patients receiving methylprednisolone; however, that does not apply to all patients and it is not possible to predict who might benefit.

\section{Conclusion}

Evidence for palliative treatments in respiratory diseases is sparse, and relevant studies only exist for COPD. The other strategies are adopted from cancer patients, where far more trials have been done. In how far results can be generalized is questionable. Many drug treatments in palliative care are off label and need to be weighed against potential risks.

There is an unmet need of larger trials of palliative care interventions, especially in nonmalignant respiratory diseases.

\section{References}

- Edmonds P, Karlsen S, Khan S, AddingtonHall J: A comparison of the palliative care needs of patients dying from chronic respiratory diseases and lung cancer. Palliat Med 2001;15:287-295.

-2 Lynn J, Ely EW, Zhong Z, McNiff KL, Dawson NV, Connors A, Desbiens NA, Claessens M, McCarthy EP: Living and dying with chronic obstructive pulmonary disease. J Am Geriatr Soc 2000;48:S91-S100.

3 Reck M, von Pawel J, Zatloukal P, Ramlau R, Gorbounova V, Hirsh V, Leighl N, Mezger J, Archer V, Moore N, Manegold C: Phase III trial of cisplatin plus gemcitabine with either placebo or bevacizumab as first-line therapy for nonsquamous non-small-cell lung cancer: AVAil. J Clin Oncol 2009;27:1227-1234.

4 Gore JM, Brophy CJ, Greenstone MA: How well do we care for patients with end stage chronic obstructive pulmonary disease (COPD)? A comparison of palliative care and quality of life in COPD and lung cancer. Thorax 2000;55:1000-1006.

5 Scano G, Stendardi L, Grazzini M: Understanding dyspnoea by its language. Eur Respir J 2005;25:380-385.

6 Galbraith S, Fagan P, Perkins P, Lynch A, Booth S: Does the use of a handheld fan improve chronic dyspnea? A randomized, controlled, crossover trial. J Pain Symptom Manage 2010;39:831-838.

7 Bausewein C, Booth S, Gysels M, Higginson I: Non-pharmacological interventions for breathlessness in advanced stages of malignant and non-malignant diseases. Cochran Database Syst Rev 2008;CD005623.

8 Schucher B, Magnussen H: Mechanical ventilation in chronic ventilatory insufficiency. Pneumologie 2007;61:644-652.
-9 Clinical indications for noninvasive positive pressure ventilation in chronic respiratory failure due to restrictive lung disease, COPD, and nocturnal hypoventilation - a consensus conference report. Chest 1999;116:521534.

10 Marciniuk D, Goodridge D, Hernandez P, Rocker G, Balter M, Bailey P, Ford G, Bourbeau J, O'Donnell DE, Maltais F, Mularski RA, Cave AJ, Mayers I, Kennedy V, Oliver TK, Brown C: Managing dyspnea in patients with advanced chronic obstructive pulmonary disease: a Canadian Thoracic Society clinical practice guideline. Can Respir J 2011; 18:69-78.

11 Casaburi R, ZuWallack R: Pulmonary rehabilitation for management of chronic obstructive pulmonary disease. N Engl J Med 2009;360:1329-1335.

12 Porszasz J, Emtner M, Goto S, Somfay A, Whipp BJ, Casaburi R: Exercise training decreases ventilatory requirements and exercise-induced hyperinflation at submaximal intensities in patients with COPD. Chest 2005;128:2025-2034.

13 Nocturnal Oxygen Therapy Trial Group: Continuous or nocturnal oxygen therapy in hypoxaemic chronic obstructive lung disease. Ann Intern Med 1980;93:391-398.

14 Medical Research Council Working Party: Long-term domiciliary oxygen therapy in chronic hypoxic cor pulmonale complicating chronic bronchitis and emphysema. Lancet 1981;i:681-686.

15 Strom K, Boman G: Long-term oxygen therapy in parenchymal lung diseases: an analysis of survival. The Swedish Society of Chest Medicine. Eur Respir J 1993;6:12641270.
16 Magnussen H, Kirsten AM, Kohler D, Morr $\mathrm{H}$, Sitter H, Worth H: Guidelines for longterm oxygen therapy. German Society for Pneumology and Respiratory Medicine. Pneumologie 2008;62:748-756.

17 Górecka D, Gorzelak K, Sliwiński P, Tobiasz $\mathrm{M}$, Zieliński J: Effect of long-term oxygen therapy on survival in patients with chronic obstructive pulmonary disease with moderate hypoxaemia. Thorax 1997;52:674-679.

18 Fletcher EC, Levin DC: Cardiopulmonary hemodynamics during sleep in subjects with chronic obstructive pulmonary disease. The effect of short- and long-term oxygen. Chest 1984;85:6-14.

19 Chaouat A, Weitzenblum E, Kessler R, Charpentier C, Enrhart M, Schott R, Levi-Valensi P, Zielinski J, Delaunois L, Cornudella R, Moutinho dos Santos J: A randomized trial of nocturnal oxygen therapy in chronic obstructive pulmonary disease patients. Eur Respir J 1999;14:1002-1008.

20 Abernethy AP, McDonald CF, Frith PA, Clark K, Herndon JE, Marcello J, Young IH, Bull J, Wilcock A, Booth S, Wheeler JL, Tulsky JA, Crockett AJ, Currow DC: Effect of palliative oxygen versus room air in relief of breathlessness in patients with refractory dyspnoea: a double-blind, randomised controlled trial. Lancet 2010;376:784-793.

-21 Young IH, Daviskas E, Keena VA: Effect of low dose nebulised morphine on exercise endurance in patients with chronic lung disease. Thorax 1989;44:387-390.

22 Chan KS, Sham MK, Tse DM, Thorsen AB: Palliative medicine in malignant respiratory diseases; in Doyle D, Hanks G, Cherny N, Calman K (eds): Oxford Textbook of Palliative Medicine. Oxford, Oxford University Press, 2005. 
23 Jennings AL, Davies AN, Higgins JP, Gibbs JS, Broadley KE: A systematic review of the use of opioids in the management of dyspnoea. Thorax 2002;57:939-944.

-24 Man GC, Hsu K, Sproule BJ: Effect of alprazolam on exercise and dyspnea in patients with chronic obstructive pulmonary disease. Chest 1986;90:832-836.

-25 Stark RD, Gambles SA, Lewis JA: Methods to assess breathlessness in healthy subjects: a critical evaluation and application to analyse the acute effects of diazepam and promethazine on breathlessness induced by exercise or by exposure to raised levels of carbon dioxide. Clin Sci (Lond) 1981;61:429-439.

-26 Dobbertin I, Dierkesmann R, Kwiatkowski J, Reichardt W: Bronchoscopic aspects of renal cell carcinoma (RCC). Anticancer Res 1999; 19:1567-1572.

27 Leach RM: Palliative medicine and non-malignant, end-stage respiratory disease; in Doyle D, Hanks G, Cherny N, Calman K (eds): Textbook of Palliative Medicine. Oxford, Oxford University Press, 2005, pp 895916.

28 Kirilloff LH, Owens GR, Rogers RM, Mazzocco MC: Does chest physical therapy work? Chest 1985;88:436-444.

-29 Irwin RS, Boulet LP, Cloutier MM, Fuller R, Gold PM, Hoffstein V, Ing AJ, McCool FD, O'Byrne P, Poe RH, Prakash UB, Pratter MR, Rubin BK: Managing cough as a defense mechanism and as a symptom. A consensus panel report of the American College of Chest Physicians. Chest 1998;114:133S-181S.

30 Christensen HR, Simonsen K, Lange P, Clementsen P, Kampmann JP, Viskum K, Heideby J, Koch U: PEEP-masks in patients with severe obstructive pulmonary disease: a negative report. Eur Respir J 1990;3:267272.

-31 Christensen EF, Nedergaard T, Dahl R: Long-term treatment of chronic bronchitis with positive expiratory pressure mask and chest physiotherapy. Chest 1990;97:645650.

- 32 Thomas J, Cook DJ, Brooks D: Chest physical therapy management of patients with cystic fibrosis. A meta-analysis. Am J Respir Crit Care Med 1995;151:846-850.

- 33 Rogers DF: Mucoactive agents for airway mucus hypersecretory diseases. Respir Care 2007;52:1176-1193.

- 34 Matthys H, Bleicher B, Bleicher U: Dextromethorphan and codeine: objective assessment of antitussive activity in patients with chronic cough. J Int Med Res 1983;11:92100.

- 35 Aylward M, Maddock J, Davies DE, Protheroe DA, Leideman T: Dextromethorphan and codeine: comparison of plasma kinetics and antitussive effects. Eur J Respir Dis 1984; 65:283-291.

36 Morice AH, Menon MS, Mulrennan SA, Everett CF, Wright C, Jackson J, Thompson R: Opiate therapy in chronic cough. Am J Respir Crit Care Med 2007;175:312-315.
7 Molassiotis A, Smith JA, Bennett MI, Blackhall F, Taylor D, Zavery B, Harle A, Booton R, Rankin EM, Lloyd-Williams M, Morice $\mathrm{AH}$ : Clinical expert guidelines for the management of cough in lung cancer: report of a UK task group on cough. Cough 2010;6:9.

38 Evald T, Munch EP, Kok-Jensen A: Chronic non-asthmatic cough is not affected by inhaled beclomethasone dipropionate. A controlled double blind clinical trial. Allergy 1989;44:510-514.

39 Holmes PW, Barter CE, Pierce RJ: Chronic persistent cough: use of ipratropium bromide in undiagnosed cases following upper respiratory tract infection. Respir Med 1992; 86:425-429.

40 Morrow GR, Shelke AR, Roscoe JA, Hickok JT, Mustian K: Management of cancer-related fatigue. Cancer Invest 2005;23:229-239.

41 Schubert C, Hong S, Natarajan L, Mills PJ, Dimsdale JE: The association between fatigue and inflammatory marker levels in cancer patients: a quantitative review. Brain Behav Immun 2007;21:413-427.

- 42 White PD, Goldsmith KA, Johnson AL, Potts L, Walwyn R, DeCesare JC, Baber HL, Burgess M, Clark LV, Cox DL, Bavinton J, Angus BJ, Murphy G, Murphy M, O’Dowd H, Wilks D, McCrone P, Chalder T, Sharpe M: Comparison of adaptive pacing therapy, cognitive behaviour therapy, graded exercise therapy, and specialist medical care for chronic fatigue syndrome (PACE): a randomised trial. Lancet 2011;377:823-836.

43 Pirraglia PA, Casserly B, Velasco R, Borgia ML, Nici L: Association of change in depression and anxiety symptoms with functional outcomes in pulmonary rehabilitation patients. J Psychosom Res 2011;71:45-49.

- 44 Brown E, Hurlow A, Rahman A, Closs SJ, Bennett MI: Assessment of fatigue after blood transfusion in palliative care patients: a feasibility study. J Palliat Med 2010;13: 1327-1330.

45 Rizzo JD, Brouwers M, Hurley P, Seidenfeld J, Arcasoy MO, Spivak JL, Bennett CL, Bohlius J, Evanchuk D, Goode MJ, Jakubowski AA, Regan DH, Somerfield MR: American Society of Clinical Oncology/American Society of Hematology clinical practice guideline update on the use of epoetin and darbepoetin in adult patients with cancer. J Clin Oncol 2010;28:4996-5010.

46 Moraska AR, Sood A, Dakhil SR, Sloan JA, Barton D, Atherton PJ, Suh JJ, Griffin PC, Johnson DB, Ali A, Silberstein PT, Duane SF, Loprinzi CL: Phase III, randomized, doubleblind, placebo-controlled study of long-acting methylphenidate for cancer-related fatigue: North Central Cancer Treatment Group NCCTG-N05C7 trial. J Clin Oncol 2010;28:3673-3679.

-47 Minton O, Richardson A, Sharpe M, Hotopf $\mathrm{M}$, Stone P: A systematic review and metaanalysis of the pharmacological treatment of cancer-related fatigue. J Natl Cancer Inst 2008;100:1155-1166.
48 Calverley PM, Anderson JA, Celli B, Ferguson GT, Jenkins C, Jones PW, Yates JC, Vestbo J: Salmeterol and fluticasone propionate and survival in chronic obstructive pulmonary disease. N Engl J Med 2007;356:775789.

49 Tashkin DP, Celli B, Senn S, Burkhart D, Kesten S, Menjoge S, Decramer M: A 4-year trial of tiotropium in chronic obstructive pulmonary disease. N Engl J Med 2008;359: 1543-1554.

50 Vermeeren MA, Creutzberg EC, Schols AM, Postma DS, Pieters WR, Roldaan AC, Wouters EF: Prevalence of nutritional depletion in a large out-patient population of patients with COPD. Respir Med 2006;100:13491355.

51 Farber MO, Mannix ET: Tissue wasting in patients with chronic obstructive pulmonary disease. Neurol Clin 2000;18:245-262.

52 Gray-Donald K, Gibbons L, Shapiro SH, Macklem PT, Martin JG: Nutritional status and mortality in chronic obstructive pulmonary disease. Am J Respir Crit Care Med 1996;153:961-966.

53 Fearon K, Strasser F, Anker SD, Bosaeus I, Bruera E, Fainsinger RL, Jatoi A, Loprinzi C, Macdonald N, Mantovani G, Davis M, Muscaritoli M, Ottery F, Radbruch L, Ravasco P, Walsh D, Wilcock A, Kaasa S, Baracos VE: Definition and classification of cancer cachexia: an international consensus. Lancet Oncol 2011;12:489-495.

54 Budweiser S, Heinemann F, Meyer K, Wild PJ, Pfeifer M: Weight gain in cachectic COPD patients receiving noninvasive positivepressure ventilation. Respir Care 2006;51: 126-132.

55 Garcia JM, Polvino WJ: Pharmacodynamic hormonal effects of anamorelin, a novel oral ghrelin mimetic and growth hormone secretagogue in healthy volunteers. Growth Horm IGF Res 2009;19:267-273.

56 Lesniak W, Bala M, Jaeschke R, Krzakowski M: Effects of megestrol acetate in patients with cancer anorexia-cachexia syndrome - a systematic review and meta-analysis. Pol Arch Med Wewn 2008; 118:636-644.

57 Strasser F, Luftner D, Possinger K, Ernst G, Ruhstaller T, Meissner W, Ko YD, Schnelle M, Reif M, Cerny T: Comparison of orally administered cannabis extract and delta-9tetrahydrocannabinol in treating patients with cancer-related anorexia-cachexia syndrome: a multicenter, phase III, randomized, double-blind, placebo-controlled clinical trial from the Cannabis-In-Cachexia-StudyGroup. J Clin Oncol 2006;24:3394-3400.

- 58 Riechelmann RP, Burman D, Tannock IF, Rodin G, Zimmermann C: Phase II trial of mirtazapine for cancer-related cachexia and anorexia. Am J Hosp Palliat Care 2010;27: 106-110

59 Lundholm K, Gelin J, Hyltander A, Lonnroth C, Sandstrom R, Svaninger G, Korner U, Gulich M, Karrefors I, Norli B: Anti-inflammatory treatment may prolong survival in undernourished patients with metastatic solid tumors. Cancer Res 1994;54:56025606. 